\title{
Regional Medical Library Planning in the Southeastern United States
}

\begin{abstract}
Planning for expanded, and more effective, information services in the United States has been stimulated by the provision for the establishment of regional medical libraries under the Medical Library Assistance Act of 1965. A description is given of a proposed decentralized, cooperative regional biomedical information system to serve the Southeastern United States.
\end{abstract}

T HE Congress of the United States passed into law on October 22, 1965, an act that has far-reaching consequences for medical libraries in the United States. The Medical Library Assistance Act of 1965 authorized funds for: construction of new, and the renovation, expansion, or rehabilitation of existing, medical library facilities; training of medical librarians and other information specialists in the health sciences; special fellowships to practitioners in the sciences related to health for the preparation of special literature projects; conducting research and investigations in the field of medical library science and related activities; improvement and expansion of the basic resources of medical libraries and related facilities; and the development of a national system of regional medical libraries.

Never before has federal financial support of this magnitude been available to the medical library profession. Yet nev-

Miss Steinke was librarian and Mr. Tannehill information scientist in the Vanderbilt University Medical Center Library in Nashville, Tennessee. This paper was presented before the 3rd International Congress of Medical Librarianship, May 1969, in Amsterdam, the Netherlands. er before have medical libraries had to cope with such an expansion of knowledge in the health sciences, an expansion that has resulted in an explosive growth in the quantity of, and major changes in the nature of, biomedical information, materials, and publications. Coupled with this problem is the lack of a "corresponding growth in the facilities and techniques necessary adequately to coordinate and disseminate among health scientists and practitioners the ever-increasing volume of knowledge and information which has been developed in the health science field. ..." "1 Faced with these considerable problems, medical libraries are beginning to receive the benefits of this legislation which was enacted to stimulate new activity in the field of biomedical information.

Prior to the legislative establishment of a national regional library program, health scientists and practitioners across the United States received regional type services officially from the National Library of Medicine at Bethesda, Maryland. This function of NLM is based on one of its primary responsibilities, which

\footnotetext{
${ }^{1}$ U.S. Congress. Public Law 89-291, S.597, October 22, 1965 (Medical Library Assistance Act of 1965). p. 1 .
} 
is to serve "as a national medical information resource for medical education, research, and service activities of federal and private agencies, organizations, institutions, and individuals."2 However, the primary sources of such services to health scientists and practitioners have been the larger medical libraries, which have for years provided limited, de facto regional library services to their immediate geographic regions. The additional funds resulting from the Medical Library Assistance Act of 1965, and its accompanying provisions of designating specific medical libraries as official regional medical libraries, have permitted these libraries to engage in programs which will improve traditional services, develop new services, reach a larger user population, improve a region's health sciences information resources and information personnel, develop more effective cooperative mechanisms among medical libraries, and improve region-wide communication networks.

It is in the expansion of de facto regional library services into fully developed, effective programs that the challenging question of "how to do it" must be grappled with, and a decision made. At the time of this writing, four regional medical library applications have been approved and funded, with approximately six others to be activated. These four are the Francis A. Countway Library of Medicine at Harvard University, Boston, Massachusetts; the University of Washington, Health Sciences Library, Seattle, Washington; the Library, College of Physicians, Philadelphia, Pennsylvania; and the John Crerar Library, Chicago, Illinois. In each instance the decision as to what the organizational system for the regional library would be, has required serious study and analysis of the

\footnotetext{
2 "Public Health Service: statement of organization functions and delegations of authority." Federal Register, 33:5, Thursday, 9 January 1968.
}

proposed region's library user population, information resources, information services, cooperative networks, geographic size, and available communication resources. Only after these parameters were defined could a general philosophy of operation be developed, and from this philosophy, bounds set for services, resources, administrative structure, and other needs.

The philosophy chosen for determining a regional library's service and administrative structure falls somewhere within the limits set by the extremes of complete decentralization and complete centralization. That complete centralization is not presently feasible for medical libraries providing service to large user groups is indicated by the National Library of Medicine's operation of the national regional library network, its decentralized indexing network, and its experimental shared cataloging network. Complete, total decentralization has not been attempted in regional medical library structures, because the disadvantages of duplication, increased cost of operation, and lack of effective administrative control are difficult to relate to a viable operation.

The Southeastern United States has also offered a challenge in the planning of a regional medical library. It is the purpose of this paper to describe the basic concepts developed at Vanderbilt University for a decentralized-cooperative regional library structure in the Southeastern section of the United States.

The Vanderbilt University Medical Center Library has for years provided limited library services outside of its immediate area of service responsibility, thus assuming the function of a de facto regional medical library. The Medical Library Assistance Act of 1965 stimulated Vanderbilt to produce a plan that would adhere to the goals of the Act in 
bringing improved and expanded biomedical information services to the large health sciences user population in the Southeastern United States, this area encompassing the states of Alabama, Florida, Georgia, Mississippi, South Carolina, Tennessee, and the Commonwealth of Puerto Rico. Guidelines published by the National Library of Medicine led to a series of meetings beginning in 1966, which brought representatives of the region's health sciences educational and library community into the active development of the regional plan and of the natural and feasible service configuration for the region.

It became evident early in Vanderbilt's planning for a regional medical library system that conditions existed in the Southeastern United States not common to the geographic regions of the regional medical libraries already established. Demographic data for the proposed region shows 9 per cent of the nation's health manpower located in the Southeast (Appendix 1). Yet to serve this large user population with medical library services, there is no single, strong, general medical information resource. Rather, the Southeastern United States has twelve medical school libraries, each having a collection of information resources that is qualitatively and quantitatively similar to the collections of the other eleven medical school libraries (Appendix 2).

With the existence of fairly equivalent medical information resource strengths in the Southeast as a parameter that could not be ignored in the design of a regional biomedical information system, a pertinent question is, "What aspects should be considered for an effective regional medical library?" The support of the school administration, library staff capability, available physical space, available computer resources, support of regional health sciences groups and li- braries, and availability of health related information resources are important to the overall capability of a library to serve as a regional library, and should be included in the aspects to be evaluated.

A proposal was filed for a Southeastern Regional Biomedical Information System (SERBIS) based on a balance between the extremes of complete centralization and complete decentralization. The regional medical library system was to be organized around a centralized administrative and triage structure located at Vanderbilt University, and a cooperative services structure which would utilize the information resource strengths at selected locations throughout the region. The philosophies which were propounded at the series of meetings held during the period 1966-1968, and which were analyzed and combined with Vanderbilt's concepts and set forth in its proposal, received support throughout the Southeast. Many of these concepts also found ready acceptance in the competing applications for a regional medical library. All told, three applications were filed with the National Library of Medicine for a regional medical library in the Southeastern United States.

The concept of the Southeastern Regional Biomedical Information System as developed by Vanderbilt University included the following objectives:

1. coordination of the strengths and competencies of health sciences information resources, personnel, and services which were available in the region;

2. the development of health sciences library materials and other information resources capable of meeting at least 90 per cent of all information demands from within the region;

3. provision for advanced training for individuals seeking careers in health science information; 
4. availability of continuing education for persons already in the field of health science information;

5. cooperation with national libraries, other regional medical libraries, and biomedical information systems for the maximum utilization of health science information resources and services;

6. continuing evaluation programs to assure the effective dissemination of health science information to the region's users.

In addition to the preceding objectives, the Vanderbilt philosophy was based on a number of other factors, primary of which were: (1) the non-existence of a single, strong, medical library; (2) the expressed support of medical librarians in the Southeast for a cooperative, decentralized approach to the regional medical library; (3) the existence of a national Regional Medical Program; and (4) the existence of the Joint University Library system in Nashville, in which the Vanderbilt Medical Center Library represents one of five divisions. The JUL were cited as an operational model of a decentralized, cooperative library system.

The developers of the Vanderbilt proposal for a regional medical library considered the feasibility of a highly centralized, large collection of the information resources necessary for effective regional service. Though such a resource structure has a number of advantages, the disadvantage of cost precluded further consideration.

The average size of the collection of ten medical school libraries in the Southeastern United States is slightly less than 65,000 bound volumes, with four libraries below the average. To attempt to bring any one of these libraries up to a collection strength necessary for highly centralized services to the Southeast would be financially prohibitive, the cost of the material being but one part of a financial picture that includes space to house the material, and personnel for processing and maintenance of the collection.

In terms of information resources, the philosophy of decentralized cooperation for the Southeastern Regional Biomedical Information System was to be carried out by the Regional Cooperative Acquisitions Plan (RECAP). Under this plan, twelve medical school libraries in the Southeastern region, each being designated a sectional library, would be responsible for in-depth collecting of information materials in specific subject fields. These subject areas were to be determined by the expressed interests of the libraries and the needs of the users, with final approval being awarded by the Regional Medical Library system's Executive Council. Under such an arrangement, it should have been possible to make available within the region at least one copy of every scholarly biomedical publication. This concept was inspired by the Farmington Plan of 1948, which provides for the acquisition of foreign material by American libraries on a subject area basis.

Decentralized cooperation was evident in other regional services to be offered to health sciences personnel throughout the Southeast, including loan of material, photoduplication, reference services, and current awareness services. The primary role for Vanderbilt in the regional medical library system was to provide back-up support to the sectional libraries and to act as a triage, or transfer, center, to administer the RML system program, to provide and coordinate information services, training programs, continuing evaluation and monitoring programs; and to develop new and improved methods of information transfer and new services as such became feasible. Each sectional medical library would act as the service center for its portion of the region, and as a develop- 
er of its peculiar subject area strengths for the benefit of the entire region. Such a service structure was in keeping with the desired factor of cooperation as stated by the medical libraries in the region.

In attempting to develop an effective regional service structure, Vanderbilt approached the problem from three different directions. First, a mechanism for the involvement of the user in policy making was established in the proposal; second, procedures for the continuing evaluation of regional services would be initiated; and third, close relationships with Regional Medical Programs for Heart Disease, Cancer, and Stroke would be established.

The administrative structure for the Regional Medical Library provided for an Advisory Council at each sectional library, each Advisory Council to comprise representatives of the health sciences users in each sectional library's service area. An Executive Council would have representatives from each of the region's Advisory Councils, as well as an elected chairman and ex officio members of the regional medical library's administrative structure. The Executive Council would formulate regional medical library system policy. These administrative mechanisms would, it was felt, insure a continuous flow of constructive criticism, recommendations, and suggestions on regional medical library policies, which would, in turn, make it possible to maintain a viable service structure.

The administrative mechanism just described is relatively subjective. Such was desirable, but objective data on services were also needed. This need was met by the evolution of a program of continuing evaluation, utilizing appropriate statistical and survey data collection and processing techniques. Evaluation activities not only lead to the improvement of operational services, but also to the development of new services.
The services to be provided by the regional medical library must be available to the user in an optimal manner in order that the system be effective. Indicated by this statement are such activities as an operable regional communications network, and trained information workers at all levels of the regional medical library system. The regional medical library proposed to approach the latter via seminars and workshops for librarians and other information personnel, a consultant service for hospital and medical libraries, the fostering of recruitment programs for personnel at the professional level, and cooperation with educational institutions in the establishment of new programs for the education and training of regional library and information specialists, and for non-professional personnel.

The development of a regional communication network was well underway among the twelve medical school libraries, which already utilized teletypewriter service connecting all but two of the proposed sectional libraries. In the future the communication network will be extended to lower levels of information service, such as the hospital, and even the individual physician. A WATS network will permit the use of the telephone over regional distances at highly economical rates. When the techniques become technically and economically feasible, such communication modes as telefacsimile, television, and computer data transmission will be utilized.

Especially important to the development of a regional communication network, as well as to other aspects of the regional medical library system, are the Regional Medical Programs for Heart Disease, Cancer, and Stroke (RMP). Each of the RMP's has the capability of establishing close, effective communication with health services personnel. It has been suggested that the regional medical library will be responsible for 
developing information services, and the RMP's will assume the responsibility for disseminating information to the user and for developing communication methodologies. Such a cooperative approach is attractive, and was fundamental to the Vanderbilt regional medical library system proposal. Initial activity in this direction is underway now in a number of RMP's across the nation, and close relationships between Regional Medical Programs and regional medical library systems will continue to develop.

The Vanderbilt Medical Center Library, as mentioned earlier, is one part of an operational, cooperative, decentralized library system known as the Joint University Libraries. In operation since 1936, it is a cooperative library project of Vanderbilt University, George Peabody College, and Scarritt College. It has been tested operationally, and has proven a number of the methodologies incorporated in the Vanderbilt philosophy. These methodologies include a centralized coordinating administration of the five member libraries (equivalent to the sectional libraries in the proposed regional medical library); development and maintenance of a union catalog; the preparation of an automated serials union list; coordination and transfer of information services; and mechanized coordination of acquisitions. The existence of successful operations such as were contemplated for the Southeastern Regional Biomedical Information System lent support to the Vanderbilt proposal.

This paper has not attempted to discuss specific details of the Vanderbilt proposal. To attempt such would merely result in a reiteration of the proposal it- self. It attempts rather to record the developments leading up to the Vanderbilt proposal and the philosophies upon which the proposal was based. Vanderbilt based its proposal for a regional medical library on cooperation and decentralization, for it is felt that the provision of effective, efficient health sciences information services, training services, evaluation services, cooperative acquisitions policy, and, in the future, information research services to the user require such a philosophy.

Medical libraries in the Southeastern United States have an enviable record of informal sharing of resources, and a formal, cooperative region-wide structure is needed to achieve full benefits from the information resources. The emerging pattern is one of an inter-institutional cooperative system designed: (1) to mobilize existing local resources; (2) to expand and build on these strengths, by a program of coordinated in-depth collecting; (3) to offer rapid access to scientific information; and (4) to coordinate the Regional Medical Library with similar developments nationally and internationally. A cooperative structure among the Southeastern United States medical libraries would offer the advantage of a system sufficiently large to take advantage of modern technological developments, and to instigate cooperative library research projects, including the application of data processing techniques for reference and research, and to prevent unnecessary duplication of facilities and services. The sharing of resources is not a simple matter but once accomplished it will result in a greater wealth for all users. 


\section{APPENDIX 1}

Demographic Data - Southeastern United States

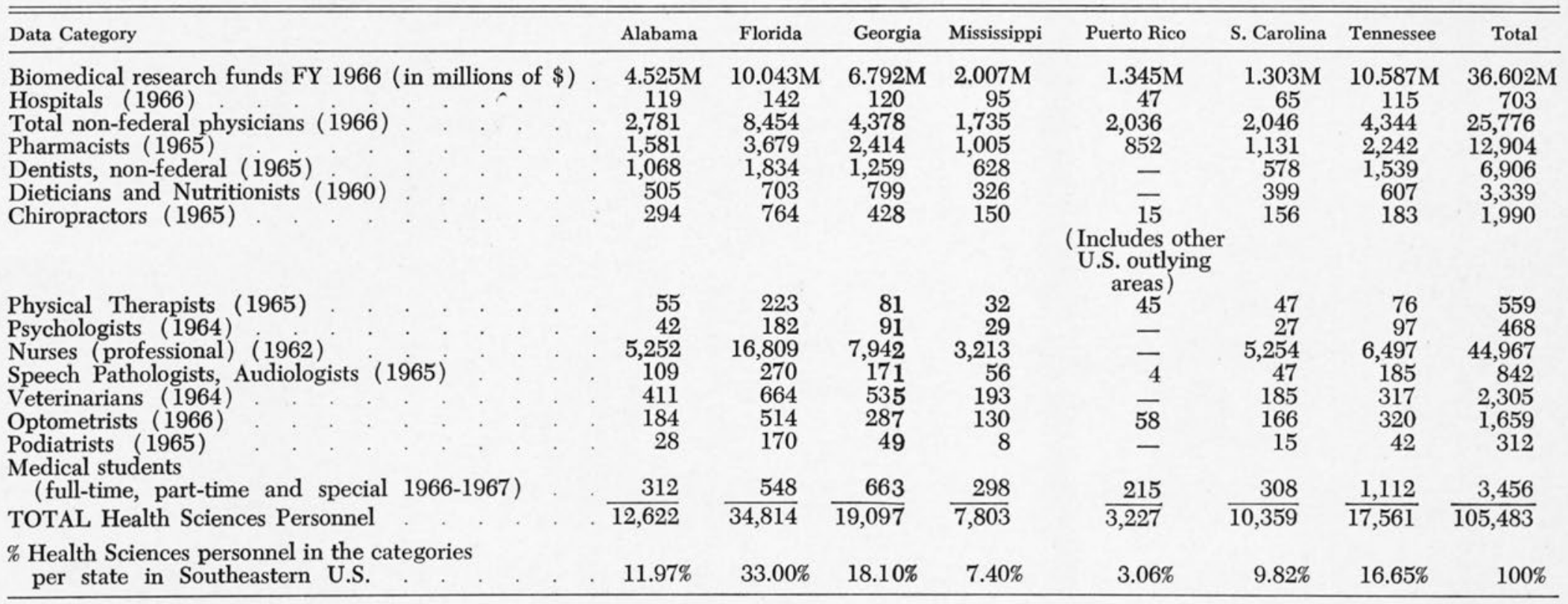

\section{NATIONAL DATA}

I. Total health services personnel in the United States, 1960. Professional, technical, and kindred

$1,167,218$

II. Percentage of the nation's health manpower in the Southeastern United States

$$
(105,483 \div 1,167,218) \times 100=9.3 \%
$$




\section{APPENDIX 2}

\section{Resource Data-Southeastern United States}

\section{General Libraries}

Volumes

University of Alabama (Tuscaloosa)

$1,039,536$

898,313

Emory University (Atlanta)

University of Florida (Gainesville)

University of Georgia (Athens)

Joint University Libraries (Peabody, Vanderbilt, Scarritt) (Nashville)

University of Miami (Miami)

University of Mississippi (Oxford)

University of Puerto Rico (Rio Piedras)

$1,047,193$

813,551

313,053

University of South Carolina (Columbia)

University of Tennessee (Knoxville).

II. Medical Libraries (March 1968)

\begin{tabular}{|c|c|c|c|c|c|}
\hline \multirow{2}{*}{$\begin{array}{l}\text { University of Alabama } \\
\text { (Birmingham) }\end{array}$} & $\begin{array}{l}\text { Bound } \\
\text { Vol. }\end{array}$ & $\begin{array}{l}\text { Current } \\
\text { Journal } \\
\text { Titles }\end{array}$ & $\begin{array}{l}\text { Collection: } \\
\text { Subject Area } \\
\text { Strengths }\end{array}$ & $\begin{array}{l}\text { Special } \\
\text { Collections }\end{array}$ & Volumes \\
\hline & 82,379 & 1,800 & $\begin{array}{l}\text { medicine, } \\
\text { dentistry, nursing }\end{array}$ & Reynolds Hist. & 6,000 \\
\hline $\begin{array}{l}\text { Emory University } \\
\text { (Atlanta) }\end{array}$ & 71,772 & 1,113 & $\begin{array}{l}\text { general medicine, } \\
\text { nursing, diabetes }\end{array}$ & $\begin{array}{l}\text { Tye (Hist. of Med.) } \\
\text { Rare Book Coll. } \\
\text { Bowcock (Diabetes) }\end{array}$ & $\begin{array}{r}1,800 \\
1,074 \\
80\end{array}$ \\
\hline $\begin{array}{l}\text { University of Florida } \\
\text { (Gainesville) } \\
\text { Medical College of }\end{array}$ & 113,122 & 1,433 & $\begin{array}{l}\text { medicine, } \\
\text { pharmacy }\end{array}$ & 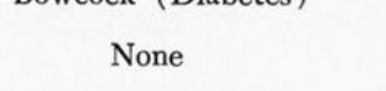 & \\
\hline Georgia (Augusta) . & 60,154 & 1,183 & general medicine & History of Med. & 3,000 \\
\hline $\begin{array}{l}\text { Meharry Medical College } \\
\text { (Nashville) }\end{array}$ & 22,300 & 466 & $\begin{array}{l}\text { neurophysiology, } \\
\text { general medicine }\end{array}$ & $\begin{array}{l}\text { Robert Hodes Memorial } \\
\text { (neurophysiology) }\end{array}$ & 102 \\
\hline $\begin{array}{l}\text { University of Miami } \\
\text { (Miami) } \\
\text { University of Mississinni }\end{array}$ & 65,000 & 1,325 & medicine, nursing & $\begin{array}{l}\text { Weinstein College (books } \\
\text { by and about physicians) }\end{array}$ & 342 \\
\hline $\begin{array}{l}\text { (Jackson) } \\
\text { University of Puerto Rico, }\end{array}$ & 57,000 & 1,700 & $\begin{array}{l}\text { medicine } \\
\text { medicine, }\end{array}$ & None & \\
\hline $\begin{array}{l}\text { School of Med. and } \\
\text { Dentistry (San Juan) } \\
\text { Medical College of }\end{array}$ & 47,974 & 1,525 & $\begin{array}{l}\text { dentistry, nursing, } \\
\text { public health }\end{array}$ & None & \\
\hline $\begin{array}{l}\text { So. Carolina } \\
\text { (Charleston) (1964-65) }\end{array}$ & 38,281 & 625 & & & \\
\hline $\begin{array}{l}\text { University of Tennessee } \\
\text { (Memphis) } \\
\text { Vanderbilt Univ. Med. }\end{array}$ & 72,062 & 1,582 & $\begin{array}{l}\text { anatomy, } \\
\text { pharmacy } \\
\text { cardiology. }\end{array}$ & None & \\
\hline Center (Nashville) & 72,868 & 1,321 & $\begin{array}{l}\text { nuclear medicine, } \\
\text { radiation } \\
\text { biophysics, } \\
\text { nursing }\end{array}$ & Hist. of Med. & 3,000 \\
\hline
\end{tabular}

